\title{
DANÇA E AS CULTURAS JUVENIS NAS AULAS DE EDUCAÇÃO FÍSICA
}

Joyce Cristina Claro Menoti, Márcia Regina Canhoto de Lima.

Universidade Estadual Paulista - UNESP, Programa de Pós-Graduação em Educação, Presidente Prudente, SP. E-mail: Joyce_cris1012@hotmail.com

\section{RESUMO}

A Dança e as atividades rítmicas representam na escola, nas aulas de Educação Física, movimentos em contextos concretos, com significações e intencionalidades, vias de expressão das Manifestações Culturais Juvenis dos alunos do Ensino Médio. A pesquisa investigou as relações dos jovens alunos com a Dança, nas aulas de Educação Física, visando compreender o nível de participação nas práticas educativas relacionadas a este conteúdo. Assumiu a metodologia qualitativa e pautou-se em pressupostos da pesquisa do tipo etnográfico na busca pela imersão no universo cultural dos fenômenos pesquisados, sem necessitar de amplo tempo em campo, mas sim, de uma imersão profunda. Por fim, constatamos que as culturas juvenis são múltiplas e, desse modo, não necessariamente a Dança, como aborda o currículo do Ensino Médio, faz parte das manifestações culturais juvenis, nessa amostra pesquisada.

Palavras-chave: Educação Física, Dança, Ensino Médio, Sociologia da Juventude e Currículo do Estado de São Paulo.

\section{DANCE AND CULTURES IN CLASSES YOUTH PHYSICAL EDUCATION}

\section{ABSTRACT}

The dance and rhythmic activities represent the school in physical education classes, movements in specific contexts, with meanings and intentions, expression pathways of Youth Cultural Manifestations of high school students. The research investigated the relationships of young students with dance, in Physical Education classes, to understand the level of participation in educational practices related to this content. He took a qualitative methodology and guided in ethnographic research of the assumptions in the search for immersion in the cultural universe of the phenomena studied, without requiring extensive time in the field, but rather, a deep immersion. Finally, we found that youth cultures are many and thus not necessarily to dance, how to approach the high school curriculum, is part of youth cultural events in this sample studied.

Keywords: Physical Education, Dance, School, Youth Sociology and Curriculum of the State of São Paulo

\section{INTRODUÇÃO}

A dança é uma herança cultural histórica, assim como ela, os jogos e os esportes fazem parte das civilizações mais remotas. De acordo com Faro (1986), a dança faz parte das manifestações humanas desde a Idade da Pedra, comprovada pelas gravuras desenhadas no interior das cavernas que mostram as atividades cotidianas dos homens dessa época, como exemplo, a pesca, a caça, a alimentação, os ritos de vida, de morte, de casamento, entre outros. Ritos esses que, geralmente, apresentavam a dança em sua composição.
A dança é, então, uma forma de linguagem, que apresenta em sua composição, sua produção e sua reprodução, significados políticos, sociais e econômicos determinados socialmente e seu ritmo é influenciado diretamente pela cultura. Dada a sua importância, a dança atualmente, está presente nos currículos escolares na disciplina de Artes, com enfoque apreciativo à arte da dança e na disciplina de Educação Física voltada à vivência e à expressão da dança como componente da Cultura Corporal de Movimento. Entretanto, esta realidade, nem sempre foi assim. Para entender os princípios da Educação Física escolar atual, é 
necessário compreender a sua trajetória histórica.

No Brasil, a Educação Física escolar sempre teve seus fins direcionados aos interesses da classe vigente no poder. Inicialmente importou métodos ginásticos europeus para compor seu conteúdo como o "Regulamento n.7" ou o "Método Francês" na época, oficialmente "obrigatórios como diretriz da prática da Educação Física na rede escolar brasileira" (GHIRALDELLI JÚNIOR, 1988, p.29).

De acordo com Ghiraldelli Júnior (1988) após esse período, ela se dividiu em cinco tendências: a Educação Física Militarista, inspirada no facismo e tinha como objetivo a obtenção de uma juventude capaz de suportar o combate, a luta, a guerra e, para isso, eliminava das aulas os incapacitados físicos. A Educação Física Higienista, de inspiração liberal e que tinha como princípio norteador, a manutenção da saúde. Ambas, não sistematizaram a Educação Física como atividade educativa, por isso, surgiu a tendência Pedagogicista que abordava a única forma de promover a "educação integral" seria por meio da educação do movimento. A Educação Física era vista como algo "útil e bom socialmente", no entanto, tinha caráter apenas instrumentista e não educativo (GHIRALDELLI JÚNIOR, 1988).

Do mesmo modo, a Educação Física Competitivista se mantém neutra ao discurso político. Nessa fase, de acordo com Ghiraldelli Júnior (1988), o esporte espetáculo ganha a cena sendo, inclusive, protegido pelo governo. E por fim, a Educação Física Popular, a qual entende que a educação dos "trabalhadores está intimamente ligada ao movimento de organização das classes populares para o embate da prática social, ou seja, para o confronto cotidiano imposto pela luta de classes" (GHIRALDELLI JÚNIOR, 1988, p.21).

Dos estudos à legalidade, a Educação Física, passa à obrigatoriedade nos currículos escolares, a partir da Lei de Diretrizes e Bases LDB de 1971, que em seu 70 artigo define a inclusão obrigatória da Educação Física, assim como, Educação Artística e Educação Moral nos currículos de 1으 2 o grau (BRASIL, 1971). O artigo apenas cita a obrigatoriedade e relata os casos de participação facultativa nas aulas. Posteriormente, em sua última versão, a LDB de 1996 (Brasil, 1996) conhecida como nova LDB dispõe no parágrafo 3 o do artigo 26 que "a Educação Física, integrada à proposta pedagógica da escola, é componente curricular obrigatório da educação básica". Dessa vez, aponta a disciplina associada ao Projeto Político Pedagógico - PPP da escola.

Diante de todos os avanços legislativos e no campo epistemológico, são elaborados documentos oficiais para o direcionamento dos objetivos a serem atingidos por todas as disciplinas no que rege a educação. Dentre eles, os Parâmetros Curriculares Nacionais - PCNs e os Currículos Estaduais, como o do estado de São Paulo (São Paulo (Estado). Secretaria da Educação, 2011).

A Educação Física, de acordo com os PCNs (Brasil, 1997) passou a ter seus fundamentos nas concepções de corpo e movimento, com foco nas relações e nas compreensões desses dois conceitos, além da consideração das dimensões: cultural, social, política e afetiva, presentes no corpo vivo das pessoas, "que interagem e se movimentam como sujeitos sociais e como cidadãos" (p.22). Nesse documento, houve um avanço significativo do conceito e dos objetivos da Educação Física escolar, ao considerar a distinção entre as características de um organismo estritamente biológico e entre o corpo, que se relaciona dentro de um contexto sociocultural, com produções culturais e conhecimentos historicamente acumulados e socialmente transmitidos (Brasil, 1997) e ao valorizar as atividades físicas sem reduzi-las ao universo motor ou esportivo.

Assim, o documento entende a Educação Física como uma cultura corporal de movimento que aborda como conteúdos algumas dessas produções culturais como: o jogo, o esporte, a dança, a ginástica e a luta. Esses blocos de conteúdos manifestam características lúdicas de diversas culturas humanas e resignificam a cultura corporal humana utilizando uma atitude lúdica (BRASIL, 1997). Passa a ser responsabilidade da Educação Física escolar, de acordo com os PCN's (Brasil, 1997), a incorporação dessas manifestações na vida dos alunos e dos seus benefícios fisiológicos e psicológicos na promoção da expressão, do lazer, da cultura, dentre outros, sem que sejam, no contexto escolar, considerados o caráter profissional da dança, do esporte, da luta, do jogo e da ginástica.

A dança e as atividades rítmicas representam na escola, a partir desses documentos, movimentos em contextos concretos, com significações e intencionalidades, 
vias de expressão das Manifestações Culturais Juvenis dos alunos no Ensino Médio. Desse modo, de acordo com Faro (1986, p.10) "a dança é uma arte bastante ligada à juventude, e com esta se move no tempo e no espaço".

No entanto, ao relacionar as Manifestações Culturais Juvenis com o contexto escolar, um grande embate é montado. A juventude, atualmente, tem maior visibilidade tanto no âmbito acadêmico, por meio de pesquisas, quanto pela esfera pública. Contudo, ainda hoje, há visões estereotipadas sobre a juventude, como por exemplo, a visão do jovem como "problema social" relacionando-os com a violência, crime, exploração sexual, drogadição, entre outros, como esclarece Abramo (2009).

A juventude, ao longo dos séculos, ainda passa por aceitação de existência. Há muitos esforços de alguns estudiosos como Pais e Groppo para que a juventude não seja entendida como uma fase da vida que antecede a entrada no mundo adulto. No decorrer da história, muitos foram os séculos em que os jovens foram negados enquanto categoria social, por não representarem os interesses e objetivos da sua sociedade, de forma que, em muitas delas havia a passagem de criança para ser adulto, por meio de ritos ou por ter atingido determinada faixa etária, sem vivenciar a juventude. Um dos maiores problemas, ainda, refere-se a essa concepção que está muito presente na escola: a visão de juventude como um "vir a ser", na qual, entendese que o jovem passa por um período de transitoriedade.

Os PCNs Ensino Médio (Brasil, 1999), ainda tratam o estudante do Ensino Médio como adolescente, jovem e adulto, entretanto, estabelece uma formação geral, em oposição à formação específica, a qual, visa a preparação científica e a capacidade de utilizar as diferentes tecnologias relativas às áreas de atuação.

Por sua vez, sabemos que a escola integra alunos de diversos contextos e históricos de vida, no entanto, muitas vezes, os jovens alunos não têm suas experiências de vida valorizadas e suas manifestações culturais não são aproveitadas no processo educacional. Segundo Carrano (2009), esse cenário gera uma situação conflitante entre os sujeitos escolares, visto que, por parte dos alunos há reclamações de que as aulas são chatas e sem sentido e os professores, por sua vez, encaram os jovens como indisciplinados e apáticos.
Apenas culpabilizar uns aos outros não irá garantir melhoras educacionais qualitativas. Para diminuir a distância entre a escola e os alunos do Ensino Médio é preciso considerar valores que façam parte das experiências comuns de todos. Dessa forma, o ensino passa a ser significativo e a escola se torna para o jovem ao invés de lugar de obrigações, um lugar, espaço e tempo de aproximação das suas manifestações culturais e de promoção da ressignificação de sentidos.

Assim, se faz necessário que a escola crie situações que possibilitem escutar os jovens alunos e valorizar suas produções, visto que, o ambiente escolar deve ser o palco das Manifestações Culturais Juvenis. Nessa perspectiva, a dança presente nas aulas de Educação Física pode ser o caminho para que haja essa aproximação, uma vez que, já faz parte das Manifestações Culturais Juvenis, no mundo da informalidade, nos meios de convívios desses jovens, nas igrejas, nas ruas, nas mídias, na sociedade em geral.

No entanto, percebemos que, nas aulas de Educação Física, os jovens participam pouco das aulas de dança. Essa constatação surgiu da minha participação no Grupo de Pesquisa: Cultural Corporal de Movimento: saberes e fazeres. As reuniões do grupo abrangem todos os participantes - graduandos, professores das escolas da rede municipal e estadual de ensino de Presidente Prudente e docentes universitários do Centro de Estudo e Pesquisa em Educação, Ludicidade, Infância e Juventude - CEPELIJ da FCT - UNESP. Na época eu era bolsista de um projeto de iniciação à docência - o PIBID - e as discussões que eram realizadas nesses encontros me chamavam à atenção para a dificuldade dos professores com determinados conteúdos da Educação Física no Ensino Médio.

Nesse sentido, a pesquisa contribuirá na compreensão da relação entre a prática da dança e as culturas juvenis, dos jovens alunos de uma sala do 3o ano do Ensino Médio de uma escola da Rede Estadual de Ensino do município de Presidente Prudente. A investigação poderá ser um caminho para o diálogo das Manifestações Culturais Juvenis e da escola, a partir da sociologia da Juventude na busca de um ambiente educativo acolhedor e significativo ao jovem aluno.

A partir das considerações abordadas até - momento, destacamos como objetivos da pesquisa: Investigar as relações dos jovens alunos com a dança, nas aulas de Educação Física, 
visando compreender o nível de participação nas práticas educativas relacionadas a este conteúdo.

\section{METODOLOGIA}

Dada a importância da pesquisa no campo da educação, que consiste em compreender os fenômenos e aprender a aprender com o diálogo da realidade, para atingir os objetivos, a pesquisa assumiu a metodologia qualitativa, visto que, teve ambiente natural como fonte de dados e o pesquisador como seu principal instrumento (Lüdke e André, 1886). Ela pautou-se em pressupostos da pesquisa do tipo etnográfica com destaque para o trabalho colaborativo entre todos os sujeitos.

Como abordagem de investigação científica, foram selecionadas estratégias da pesquisa do tipo etnográfico, visto que trata-se da utilização dos mesmos instrumentos da pesquisa etnográfica, contudo, essa abordagem permite que $o$ pesquisador permaneça menos tempo em campo, desde que ele faça parte do mesmo universo cultural do campo pesquisado. Desse modo, as estratégias de pesquisa do tipo etnográfico são pertinentes a pesquisas como essa de pós-graduação, nas quais há prazos determinados para sua realização.

Para o alcance dos objetivos propostos, em primeiro momento, foi realizado 0 levantamento bibliográfico com autores selecionados que estudam a temática da pesquisa, especificamente, autores que abordam as culturas juvenis pautadas em estudos no campo da Sociologia da Juventude e a Dança na Educação Física escolar. Nessa etapa de pesquisa enfocamos nosso olhar na leitura, compreensão e discussão dos documentos e dos currículos oficiais que norteiam a educação e a Educação Física, especialmente, no currículo do estado de São Paulo.

Posteriormente, atendemos aos requisitos éticos como a obtenção da aprovação do comitê de ética, devidamente registrado no CEP - Plataforma Brasil, no do parecer 1.515.176, autorização da escola e entrega de Termo de Consentimento Livre e Esclarecido aos jovens alunos e aos seus pais.

Os sujeitos da pesquisa englobam os jovens alunos de uma sala do 3 o ano do Ensino Médio, estudantes do período diurno, de uma escola da Rede Estadual de Ensino do município de Presidente Prudente e os dados da pesquisa foram coletados no período de um ano letivo.

Como procedimentos metodológicos, contamos com diversas fontes de evidências, a partir dos instrumentos de pesquisa como: questionários, observação participante, diário de campo e fotografias.

Inicialmente, foram aplicados os "questionários 1" para todos os alunos das cinco salas dos 3o anos do Ensino Médio da escola parceira, a fim de selecionar a amostra de pesquisa. $O$ questionário foi elaborado sem a identificação do aluno na busca pelas respostas mais fidedignas possíveis. As perguntas terão por objetivo identificar a sala que apresentar a maior porcentagem de alunos que não gostam de participar das aulas de Educação Física com o conteúdo Dança. Após essa filtragem e seleção da sala que foi investigada, aplicamos os "questionários 2" para todos os seus alunos.

Posteriormente, foram realizadas as observações participantes em todas as aulas de Educação Física dessa turma, haja vista que ela permite ao pesquisador que ele mantenha contato pessoal e estreito com o fenômeno.

Por fim, se necessário, a pesquisadora poderá realizar entrevistas exploratórias com os alunos, a partir da relação dos dados dos questionários com as observações, no surgimento de alguma dúvida que necessite de esclarecimentos.

\section{RESULTADOS}

Os resultados apontam que nas aulas de Educação Física, os jovens alunos do Ensino Médio sentem-se tímidos e encaram a Dança, na sua forma institucionalizada, na qual, representa um conteúdo da disciplina, que dependerá da sua participação para atingir determinada nota, mesmo a Dança fazendo parte do seu cotidiano extra-classe. Há também o fator histórico da Dança ter adentrado os meios escolares por meio do Ballet Clássico, o qual era destinado, em sua maioria, às meninas. Esse fato determina, até hoje, a participação dos meninos, que representaram o maior percentual de não participantes das aulas de Dança na Educação Física.

No entanto, as aulas de Educação Física, muita vezes, pelo fato de acontecem na quadra, um espaço que, geralmente, todos os agentes escolares têm acesso e, muitas vezes, é caminho para o banheiro ou rota bastante utilizada de acesso aos outros lugares da escola, expõe corporalmente esse jovem aluno impossibilitando a sua efetiva participação.

Notamos, também, através das observações que determinados ritmos têm mais 
proximidade com as Culturas Juvenis, como é o caso do sertanejo, contrariando o Hip-Hop, abordado no currículo do estado de São Paulo. Tais conteúdos tiveram maior participação dos jovens alunos e demonstraram que a Dança é uma via de aproximação das Culturas Juvenis, uma vez que eles expuseram a felicidade e a importância de tal conteúdo em sua vida, por meio de relatos.

A professora tem uma postura de proximidade com os alunos e tenta acolher as Manisfestações Culturais Juvenis nas atividades, no entanto aponta a dificuldade em trabalhar com esse conteúdo.

\section{DISCUSSÕES}

Os jovens alunos ao se negarem a participarem de algumas aulas de Dança, demonstraram que a exposição corporal é um dos motivos desse impedimento, bem como, em relatos informais apresentaram a falta de intimidade com o Hip-Hop.

O currículo (São Paulo, 2011) aponta que nas aulas de Dança as culturas juvenis são representadas pelo Hip-Hop, contrariando os dados obtidos. Assim, apontamos que as culturas juvenis são múltiplas e não necessariamente correspondem a estereótipos, abrindo um campo para novas investigações.

\section{CONSIDERAÇÕES FINAIS}

O fato é que a escola representa um espaço que concentra jovens de diversas culturas, a fim de alcançar um único objetivo: a educação. Para que o seu objetivo seja atingido no Ensino Médio, se faz necessário criar condições de aproximação das Culturas Juvenis, uma vez que, esse jovem aluno é cobrado em obter bons rendimentos nos vestibulares, não o possibilitando vivenciar suas manifestações culturais nesse ambiente tão sério. Nesse sentido, as aulas de Educação Física, por meio da Dança enquanto eixo de conteúdo pode possibilitar tais vivências.

Se o jovem aluno tiver um ambiente escolar acolhedor e que privilegia as vivências das suas manifestações culturais, o ensino dos conteúdos será significativo e garantirá a ele um ensino de melhor qualidade. Desse modo, a Dança como conteúdo escolar se demonstra de essencial importância no alcance de tais objetivos, uma vez que, acolhe as Manifestações Culturais Juvenis e representa a expressão das Culturas Juvenis no ambiente escolar.

\section{REFERÊNCIAS}

ABRAMO, Helena Wendel. Considerações sobre a tematização social da juventude no Brasil. Revista Brasileira de Educação, n. 5, ago. 2009. BRASIL. Constituição (1967). Lei de diretrizes e bases da educação nacional: Lei no 5.692, promulgada em 11 de agosto de 1971. Disponível em:

http://www.planalto.gov.br/ccivil_03/leis/L5692. htm>. Acesso em 30 jul. 2015.

BRASIL. Constituição (1988). Lei de diretrizes e bases da educação nacional: Lei no. 9.394, promulgada em 20 de dezembro de 1996. Disponível em: < http://www.planalto.gov.br/ccivil_03/LEIS/L9394 .htm>. Acesso em 30 jul. 2015.

BRASIL. Secretaria de Educação Fundamental. Parâmetros Curriculares Nacionais: Educação Física. Secretaria de Educação Fundamental. Brasília: MEC/SEF, 1997. 96p.

BRASIL. Secretaria de Educação Média e Fundamental. Parâmetros Curriculares Nacionais: Ensino Médio. Ministério da Educação, Secretaria de Educação Média e tecnológica. Brasília: Ministério da Educação, 1999, 364p.

CARRANO, Paulo Cesar Rodrigues. Identidades Culturais Juvenis e escolas: arenas de conflitos e possibilidades. Diversia, CIDPA Valparaíso, n.1, p. 159-184, abr. 2009.

FARO, Antonio José. Pequena história da dança. Rio de Janeiro: J. Zahar, 1986, 149 p.

GHIRALDELLI JÚNIOR, Paulo. Educação física progressista: a pedagogia crítico-social dos conteúdos e a Educação Física brasileira. São Paulo: Loyola, 1988. v. 10.

LÜDKE, Menga ; ANDRÉ, Marli Eliza Dalmazo Afonso. Pesquisa em educação: abordagens qualitativas. São Paulo, Editora Pedagógica e Universitária, 1986. 99 p.

SÃO PAULO (Estado) Secretaria da Educação. Currículo do Estado de São Paulo: linguagens, códigos e suas tecnologias. 2. ed. - São Paulo: Secretaria de Estado da Educação, 2011. 260 p.

Recebido para publicação em 30/08/2016

Revisado em 02/09/2016

Aceito em 05/09/2016 